DOI: $10.17805 / z p u .2016 .1 .11$

\title{
Феномен мобилографии как новая форма репрезентации идентичности
}

\author{
Т. С. ПАНИОТОВА, М. В. МИТРОХИНА \\ (ЮЖНЫЙ ФЕДЕРАЛЬНЫЙ УНИВЕРСИТЕТ, РОСТОВ-НА-ДОНУ)
}

В статье анализируется феномен мобилографии в контексте современной молодежной культурной среды и в тесной взаимосвязи с проблемой культурной идентичности. Авторы выдвигают предположение о том, что мобильная фотография на данном этапе развития общества способна служить одним из средств культурной самоидентификации молодежи, способов ее выстраивания и форм репрезентации.

Культурная идентичность понимается авторами как интерсубъективная сторона культуры или культура, специфическим образом интериоризированная. Мобилография (мобильная фотография) - собирательное название, которым обозначают фотографии, сделанные на устройство, не предназначенное для профессионального фотографирования, явление, достигшее огромнейших масштабов в последние годы.

Феномен мобилографии анализируется с помощью семиотического, структурного и культурологического методов. Приводятся результаты эмпирического исследования авторов (2015 г.) с целью выявления новых специфических форм репрезентации культурной идентичности посредством определенных жанров любительской фотографии и их авторская классификация. Исследование проводилось на основе фотографий, опубликованных на личных страницах россиян в возрасте от 16 до 30 лет в социальных сетях «ВКонтакте», "Одноклассники», Instagram, Flickr. Данные социальные сети были избраны ввиду наибольшей популярности среди российской молодежи и обилия фотоконтента. В итоге были изучены и интерпретированы 1000 фотографий, сделанных на мобильный телефон владельцами 100 аккаунтов и блогов.

Авторы отмечают, что реализация и презентация культурной идентичности посредством мобильной фотографии происходит прежде всего через идентификацию представителей молодого поколения с отчим домом, малой родиной и большой родиной; знаковыми историческими событиями и людьми; объектами культурного и природного наследия. К креативным формам, акцентуирующим презентацию культурной идентичности, авторы относят постановочные фотографии, флешмобы, фотоакции и другие виды экспрессивной фотографии.

Исследование показало, что феномен мобильной фотографии выступает важным способом самоопределения и самопрезентации молодых людей в культуре, трансформируя процессы приобретения идентичности, в частности культурной.

Ключевые слова: идентичность; атрибуты идентичности; культурная идентичность; мобилография; мобильная фотография; селфи; интернет-коммуникация; социальные сети; молодые люди; репрезентация; коннотация; коммуникация

\section{ВВЕАЕНИЕ}

C овременная социокультурная ситуация характеризуется переходом от книжной культуры к экранной, замещением традиционных форм вербального и письменного общения новыми формами визуальной коммуникации. Соответственно, трансформируются способы и формы репрезентации идентичности человека в культуре. Такие классические формы, как автобиография, автопортрет, дневниковые записи, письмо, монолог и др., дополняются новыми, порожденными распространением и постоянным усложнением высоких технологий. Возникает феномен мобилографии, представляющий собой новую форму репрезентации идентичности с помощью фотографий, сделанных на устройство, не предназначенное для профессионального фотографирования.

Одним из доказательств того, что данное явление становится важной частью общественной жизни, может служить всевозрастающая популярность смартфонов 
с фотокамерами, возникновение на рынке специальных съемных объективов для телефонов, приспособлений для селфи (самофотографирования), а также появление и развитие тематических социальных сетей, направленных на общение через посредника - фотографию.

Но какова реальная роль мобилографии в культуре, какие функции она выполняет? Что это - очередной виток моды, новая форма коммуникации или нечто большее? Является ли мобилография актуальным способом репрезентации культурной идентичности в молодежной среде? Попытку дать ответы на эти вопросы содержит настоящая статья. Мы предположили, что мобильная фотография способна служить средством культурной самоидентификации современной молодежи, одним из важных способов ее выстраивания и выражения. Культурная идентичность в этом контексте понимается в самом общем виде, т. е. как ответ на вопрос: «Кто я в культуре?»

\section{К ОПРЕАЕАЕНИЮ ПОНЯТИЙ}

Понятия культуры и идентичности в культурологии и антропологии рассматриваются как тесно взаимосвязанные и неотделимые друг от друга и от человека. Еще Г. Зиммель подметил, что «в точном смысле слова только человек может быть предметом культуры, ибо он является единственным известным нам существом, обладающим изначальным побуждением к самоосуществлению» (Зиммель, 1996: 477).

Поэтому, чтобы определить идентичность, требуется сначала понять, что такое культура.

Современные исследователи ушли далеко вперед от распространенного в 50-е годы ХХ в. определения культуры как совокупности материальных и духовных ценностей, выработанных человечеством на протяжении его многовековой истории, либо как собрания принятых в обществе «моделей поведения». Начиная с 1970-х годов, когда К. Гирц в своей книге «Интерпретация культур» со ссылкой на М. Вебера определил культуру как «паутину смыслов», культурология дрейфует к концепциям, сводящим культуру к сфере символических событий. Согласно Гирцу, человек - «это животное, висящее на сотканной им самим паутине смыслов», а символическое - это не изолированный мир, а измерение, присущее всем видам социокультурных практик. Цель ученого, по мнению Гирца, и состоит в выявлении и разъяснении значений и смыслов во всех внешне загадочных выражениях социального (Гирц, 2004: 11).

Культурные значения, с одной стороны, объективируются в виде артефактов или форм поведения, называемых «культурными формами» (произведения искусства, обычаи, и др.), в то же время они интериоризируются в виде габитуса коллективных стереотипизированных схем или социальных представлений. В первом случае имеем дело с объективированным символизмом и народной культурой, а во втором - с интериоризированными формами или формами, инкорпорированными в культуру (Bourdieu, 1985: 86). Разумеется, между двумя этими формами культуры существует диалектическая связь. С одной стороны, интериоризированные формы происходят из коллективного опыта и опосредованы объективированными формами культуры; с другой - невозможно воспринимать и интерпретировать внешние формы культуры вне когнитивных схем или габитуса.

Резюмируя, можно сказать, что культура есть социальная система смыслов, интериоризированных субъектами в виде устойчивых схем или общих представлений и объективированных в символических формах, по Э. Кассиреру (Кассирер, 2002), в конкретных социально-исторических и пространственно-временных контекстах. 
Что же касается идентичности, то она представляет собой не что иное, как интерсубъективную сторону культуры, или культуру, специфическим образом интериоризированную. Она немыслима без присвоения культурных стереотипов и признаков, характерных для определенной социальной среды, культуры или общности. Но при этом, как писал Ю. Хабермас, «каждая самопрезентирующаяся субъективность сосредоточена на самой себе и представляет мир как целое своим собственным уникальным способом» (Хабермас, 1992: 44), что служит основанием для понимания ее отличия от Аругого. Идентичность можно трактовать как совокупность характеристик, представлений, поведенческих схем, принадлежащих членам одной группы и предположительно не принадлежащих (или не полностью принадлежащих) тем, кто находится за ее пределами.

Сама идея «особости» предполагает наличие элементов, маркеров, характеристик, отличительных черт, способных зафиксировать специфику, уникальность или субстанциональность индивида. Г. Хименес выделяет среди них следующие элементы:

1) принадлежность к множественным сообществам (категории, группы, социальные сети, большие коллективы);

2) наличие набора нетипичных или реляционных свойств;

3) биографическое повествование, которое содержит историю жизни и социальную траекторию личности (Giménes, 1997: 12-13).

Таким образом, разграничительная функция идентичности позволяет индивиду не только понять особенности своей культуры, провести границу между «своими» и «чужими», но и выявить собственную уникальность среди членов своей социальной группы.

\section{ПРОЯВАЕНИЯ ИАЕНТИЧНОСТИ}

Хотя говоря об идентичности, мы всегда имеем в виду социальных акторов, следует помнить, что идентичностью обладают конкретные индивиды, наделенные сознанием, памятью и психическими особенностями. Можно говорить о двойном наборе отличительных социокультурных признаков идентичности человека. К одним относятся признаки социальной принадлежности, которые включают идентификацию индивида с различными категориями и социальными группами; другие представляют собой свойства, определяющие уникальность и своеобразие конкретного субъекта. Первые выделяют общие черты, в то время как вторые подчеркивают различия, и только взятые вместе они формируют представление о многомерном самобытном субъекте.

О каких группах социальной принадлежности идет речь? Самые главные - хотя и не единственные - это социально-классовая, этническая, территориальная (город, регион, государство), демографическая (возрастная и половая) группы. Индивид имеет родительскую, а затем собственную семью; профессию и сообщества по интересам; он осознает себя гражданином государства и частью определенного социального слоя, трудового коллектива, включается в отношения социального партнерства с другими людьми. Социальные связи образуют важнейшую составную часть идентичности человека. Более того, рост социальных связей и групп принадлежности не только не разрушает индивидуальную идентичность, но, напротив, ее укрепляет и усиливает, потому что расширение круга общения и сфер деятельности минимизирует возможность появления идентичностей с однотипным набором характеристик. На это обращал внимание еще Г. Зиммель. 
Что же касается специфических свойств, то они еще более многочисленны, разнообразны и изменчивы, так что приводимый ниже перечень можно считать открытым, а не стабильно окончательным.

Среди атрибутов, определяющих уникальность и своеобразие конкретного субъекта, можно выделить:

- «характерологические» свойства;

- стиль жизни, проявляющийся, в частности, в потребительских предпочтениях;

- личную сеть близких отношений;

- эмоциональную привязанность к определенным материальным объектам;

- личную биографию.

Характерологические атрибуть - это набор признаков, часть которых касается индивидуальных свойств личности (например, интеллектуальный, настойчивый, творческий человек), а другая часть - ее социальных взаимоотношений (например, спокойный, дружелюбный, общительный, сентиментальный человек).

Стиль жизни - это система знаков, которые содержат информацию об идентичности человека, а потому могут служить индикаторами идентичности. Не в последнюю очередь эта система связана с личностными предпочтениями в сфере потребления. Огромное разнообразие и множественность продуктов потребления, предлагаемых рекламой и маркетингом, позволяет осуществлять выбор стиля жизни в широком диапазоне. Можно выбрать, например, «зеленый стиль» жизни, который будет выражаться в потреблении особых продуктов питания, особом отношении к природе и т. А.

Аичная сеть близких отношений человека (ближайшие родственники, друзья, товарищи, женихи и невесты и т. А.), о которой пишет французский социолог Э. Морен, также может выступать фактором дифференциации (Морен, 2005). Аействительно, в жизни каждого человека имеется узкий круг лиц, каждое из которых представляет собой альтер эго, т. е. его «другое я». И поскольку через общение с представителями этого круга происходит как бы расширение и удвоение его личности, постольку исчезновение «другого», будь то переезд или уход из жизни, может ощущаться как незаживающая рана или невосполнимая утрата. Отсутствие этого ближнего круга порождает у людей чувство невыносимого одиночества (там же: 157).

Еще один атрибут - это әмочиональная привязанность к определенным материальным объектам, которые являются частью владений человека: его собственное тело, дом, автомобиль, собака, музыкальный репертуар, стихи, какой-то портрет, пейзаж и т. А. У. Ажеймс (тж. Ажемс) писал: «В самом широком смысле личность человека составляет общая сумма всего того, что он может назвать своим: не только его физические и душевные качества, но также его платье, дом, жена, дети, предки и друзья, его репутация и труды, его имение, его лошади, его яхта и капиталы» (Ажемс, 1991: 81).

Но то, что в наибольшей степени отличает и выделяет индивида среди других людей, - это его личная биография, представленная в виде «истории жизни». А. Пиццорно называет это «биографической личностью», а Э. Аипиански - «внутренней идентичностью». Именно на этом уровне близости (между знакомыми, товарищами, друзьями или влюбленными) обычно происходит взаимное личностное самораскрытие, когда на потребность в углубленном познании ( РРасскажите мне о себе, кто вы: я ничего не знаю о вас») отвечают автобиографическим повествованием, репрезентируя себя как неповторимую индивидуальность. 
Заметим, что выделенные нами социокультурные презентации идентичности могут быть представлены различными способами - как в классических, так и в актуальных формах. Одной из них является мобилография.

\section{МОБИАОГРАФИЯ КАК СПОСОБ ПРЕЗЕНТАЦИИ КУАБТУРНОЙ ИАЕНТИЧНОСТИ}

В наши дни мобильная фотография становится одной из основных форм общения, одним из важнейших способов обмена информацией, а изображение - центральным конструктом мышления современного человека. Аоступность и удобство использования «мобильных камер» открывают новые возможности для фотографирования множества моментов из жизни, ранее ускользавших от внимания, мгновенно распространять и публиковать фотографии, находиться на связи со всем миром здесь и сейчас.

Таким образом, создаются разветвленные коммуникационные сети, новые формы диалога и полилога с определенными правилами и механизмами функционирования, где отдельно взятые частные объект или явление, отраженные через фото, становятся достоянием общественности. Ааже сам субъект, зачастую соединяя в себе одновременно роли operator' а (фотографа), spectrum' а (референта или симулякра) и spectator' а (зрителя) (Барт, 2011: 24), становится частью транслируемой информации, объективируется через передачу своего изображения или портрета (там же: 31-32), конструирует идентичность с помощью фотографий.

В первой половине 2015 г. нами было проведено специальное исследование, нацеленное на изучение репрезентации культурной идентичности в молодежной среде посредством мобильной фотографии. Материалом настоящего исследования стали фотографии, опубликованные на личных страницах (в профилях, общедоступных альбомах и лентах блогов) россиян в возрасте от 16 до 30 лет в социальных сетях «ВКонтакте», «Одноклассники», Instagram, Flickr. Аанные социальные сети были избраны ввиду наибольшей популярности среди российской молодежи и обилия фотоконтента. В итоге было изучено и интерпретировано 1000 фотографий, сделанных на мобильный телефон владельцами 100 аккаунтов и блогов. Также оценивались сопутствующие надписи, пояснения и хэштеги, если таковые были даны автором в исходнике. Аифференциация по половому, социально-экономическому, религиозному и иным признакам, выборка географических ареалов не проводились, поскольку была поставлена задача представить обобщенную картину для современной России, молодые жители которой в большинстве регионов являются носителями схожей интернет-культуры.

Молодые люди были избраны для исследования не только по причине наибольшей близости в своей практике к современным технологиям, но и потому, что они, очевидно, перенесут определенные навыки социальных интернет-презентаций, особенности сформированного виртуальной культурой восприятия и обмена информацией, общения и творческой деятельности в дальнейшую взрослую жизнь. «Поколение Си» (Solis, 2012: Электронный ресурс), взращенное на волне революции цифровых технологий, постепенно изменяет образ жизни общества, где цифровые инновации становятся новым орудием труда, необходимым для существования, тем самым меняется и культура как специфический способ бытия и деятельности человека. Следовательно, и выражение культурной идентичности должно приобретать иные формы, соотноситься с визуальной доминантой мышления современных дюдей, что мы и пытались проследить в данном исследовании. 
Анализ фотографий был проведен на основе семиотического метода, сформулированного Р. Бартом для фотографии с учетом специфических приемов коннотации (Барт, 2003: 382-387), и структурного метода, приведенного П. Штомпкой в изложении принципов визуальной социологии (Штомпка, 2007: 89-90). По Р. Барту, коннотация - это наложение вторичного смысла на фотографическое сообщение; она призвана закодировать фотографию, не имеющую кода. Исследователь выделяет ряд приемов коннотации: монтаж, поза, объекты, фотогения, эстетизм и синтаксис, а также текст, сопровождающий снимок (Барт, 2003: 382-387). На наш взгляд, вышеперечисленные приемы выступают универсальными понятиями для семиотического анализа фотографического сообщения, актуальными и в условиях циркуляции цифровой фотографии. Однако лингвистический детерминизм по отношению к фотографии и ее пониманию является излишним, так как не допускает возможности рассматривать целостно ту культурно значимую информацию, которая скрыта в фотографическом изображении, имеющем и пикториальные свойства. П. Штомпка в учебнике «Визуальная социология» описывает различные методы исследования фотографии в социогуманитарных науках, включая разработанный им метод структурного анализа. По его мнению, фотография есть внешний знак неких важнейших структур общественной системы, лежащих глубже коннотаций и денотаций. Автор выделяет основные элементы общественной структуры, среди которых человеческая деятельность, общественные правила, идеи и жизненные возможности, и подвергает фотографию анализу с позиции данных составных частей (Штомпка, 2007: 89-90). Безусловно, основная проблематика, поднимаемая Штомпкой, социологическая, но его метод рассмотрения визуальных объектов существенно дополняет чисто семиотический, позволяя более целостно подойти к изучению фотографии. Однако высшим уровнем исследования фотографических изображений как носителей культурных смыслов должна стать, на наш взгляд, именно культурология, позволяющая интерпретировать наработки предыдущих уровней с точки зрения общечеловеческих культурных закономерностей, архетипов и ценностей.

Таким образом, в настоящем исследовании выделены уровни декодирования смыслов с различными методологическими подходами: первый - семиотический, второй структурный и третий - культурологический способы анализа и интерпретации.

В ходе такого декодирования фотографии были объединены нами в некоторые смысловые группы по принципу схожести тематики изображенного, коннотации, характера выражения культурной идентичности.

Следуя обозначенной методике и используя вышеперечисленные критерии, можно выделить следующие группы фотографий.

1. Фотографии «родных мест» - домов, улии, родного для фотографа города или поселка в целом, мест сочиализаиии и пр. Они выполняют функции документации, презентации и интеракции, носят информационное, эстетическое или критическое и другие назначения. Кроме непосредственно «любования», описания или демонстрации мест фактического пребывания человека, данные тематические фотографии часто выражают определенную культурную идентичность, привязанность фотографа к своему малому культурному субстрату. Подобные фото можно интерпретировать на основе естественного языка следующими ассоциациями: «дом, милый дом», «отчий дом», «Родина», и схожая коннотация часто задается самим автором посредством сопровождающего текста. Они передают ощущение причастности, помогают молодому человеку выработать определенную систему отличий и символов культурной 
«самости». Аалее фотографии малой родины встраиваются в синтагматическую последовательность, включая в себя все значимые для определенного субъекта места, и в парадигматическую целостность, «соседствуя» на интернет-страницах с фотографиями большой родины. В итоге реализуется целостное представление о своей культурной принадлежности с помощью фотографии. Также в зависимости от того, какому spectator'y адресованы подобные фото, разнится способ кодирования смыслов и их представления. Аля «своих» значимыми могут быть места, выпадающие из массовой известности и репертуара общего кода, а для «чужих» чаще всего демонстрируется определенный круг стандартных изображений, например основные достопримечательности города.

2. Фотографии объектов исторического, культурного и природного наследия как самостолтельные, так и с присутствием людей (селфи, фото на фоне чего-либо). Значения таких фотографий могут совпадать с первой группой, но к ним добавляются и специфические оттенки. Так, фотографии, представленные в определенных тонах, ракурсах, эмоционально положительно окрашенные, передают восхищение, гордость и радость причастности к великому; другие же, напротив, задают критическую коннотацию, могут демонстрировать удрученность и озабоченность фотографа забвением или разрушением памятников, разделять скорбь, если это мемориал. В целом традиция фотографирования рядом с памятными местами, объектами из прошлого популярна и сейчас, и это обусловлено желанием людей, особенно молодых, прикоснуться к истории, почувствовать себя частью вековой народной жизни и своей культуры, лучше понять собственное место в ней. Аелясь своей фотографией какого-либо памятника, человек в очередной раз выполняет своеобразный ритуал запоминания, демонстрирующий его включенность в данную культурную общность. Причем репертуар таких объектов будет сообщать, к какой именно общности молодой человек себя причисляет, насколько обширна его историческая память и сильна связь с предками/событиями/традициями. Кроме того, сами объекты культурного наследия, отображенные на фотографии, представляется возможным трактовать как символы, олицетворяющие то или иное обобщенное понятие, представление, характерное для данной культуры и для определенного человека, причем наиболее условная связь между означающим и означаемым наблюдается во втором случае.

3. Фотокосплей (фотоинсиенировка, постановочная фотография). Это один из новых стилей современной фотографии. Под словом «косплей» подразумевается буквально «игра в переодевание» (сокр. от англ. costume play - костюмированная игра), где необходимым условием всего этого вида творческой деятельности является непосредственно создание аутентичного внешнего облика, соответствующего в мелких деталях, например, традиционной крестьянской одежде XIX в. в России либо образу Хозяйки Медной горы. К этой группе фотографий относятся такие изображения, где человек одет в национальную одежду, причем одет согласно каноном традиционного ношения одежды определенного этноса либо воплощает образ из фольклора или другого вида традиционного искусства. Сюда также мы включили фото с исторических инсценировок, постановок, а также фото субъектов и объектов, специально стилизованных под определенную эпоху или культуру. Фотографии такого типа несут в себе не только эстетическое и развлекательное назначение, но и демонстрируют стремление молодежи выразить свое духовное самосознание, прочувствовать идентичность через предметы материальной культуры, через знаки причастности к определенной социокультурной общности. Сейчас прослеживается некоторая тенденция 
возрастающего интереса к отечественной культуре, мода на «свое», традиционное, пусть и во внешнем выражении. Но проявившаяся потребность лежит в культурной плоскости, возможно, более глубокой, чем может показаться на первый взгляд.

4. Фотографии репортажного характера с массовьх мероприятий или с других собъттий, где задействованы группь людей. Аанные фотографии интересны в синтагматической последовательности, поскольку при таком рассмотрении описывают взгляд автора на происходящее, выявляют главное для него и определенных лиц. Подобные серии фото, как правило, фиксируют присутствие человека на определенном событии. Но наиболее активная функция их выполняется после самого мероприятия, когда фотографии публикуются в Интернете, на них отмечают людей и т. А. Таким образом, временная общность восстанавливается в Сети, участниками коммуникации осознается свое единство, особенно ярко - в результате общенародных событий, что способствует интеграции, солидарности и взаимодействию.

5. «Кричашие фотографии», фотоакиии, флешмобь, мобильная фотодокументалистика. Эта группа образована фотографиями, привлекающими внимание общественности к социальным, экологическим, нравственным и другим проблемам. Они направлены на помощь людям, животным, объектам культурного или иного наследия в своем прямом назначении, а не коннотативно, как в предыдущих группах. Могут использовать экспрессивные и суггестивные методы воздействия на зрителя, но в целом должны вызывать чувства сострадания, сопереживания, вины и пр., побуждать к действию. Благодаря таким фотоакциям неравнодушные молодые люди стремятся оживить гражданское самосознание, запустить механизм взаимопомощи. В итоге некоторым образом производится и процесс культурной самоидентификации, когда индивид осознает свою роль в определенной общности, признает ее ценности своими и приоритетными, выполняя своеобразный долг перед носителями своей культуры. Так можно распознать современного «героя», волонтера-активиста, просмотрев его страничку в Instagram.

Естественно, в количественном соотношении выделенные группы фотографий представлены у владельцев аккаунтов неравномерно. Около 47\% из всех изученных фотографий занимает первая группа - фото родных мест, 28\% составляет вторая группа - фото различных видов наследия, 16\% занимают фотографии четвертой группы - репортажного характера с массовых мероприятий, 5\% - пятая группа фотоакции и фотодокументалистика, около 4\% приходится на фотографии третьей группы - фотокосплея. Аанная статистика демонстрирует приоритет в репрезентации молодыми людьми своей культурной идентичности через фото мест обитания и социализации, т. е. того, что окружает с детства, а также фотографий признанного в нашей культуре исторического и природного наследия, различных памятников. Фотографии с массовых мероприятий также часто встречаются, поскольку в основном и делаются для публикации в социальных сетях, могут свидетельствовать и о желании подтверждения своей культурной идентичности другими. Фотографии, используемые во флешмобах, документирующие что-то, привлекающие внимание общественности к проблемам, являются контентом, несущим зачастую определенную эмоциональную окраску, которая не всегда положительна, кроме того, многие фото этой группы получаются случайно, чем обусловлено их количественное присутствие. Самым нераспространенным типом презентации культурной идентичности через фотографию стали фотоинсценировки и фотокосплей, пусть и набирающие популярность с каждым днем, однако специфически маркированные. 


\section{ЗАКАЮЧЕНИЕ}

Как показали результаты исследования, мобилография является актуальной формой культуротворчества и выполняет важные функции в современной молодежной культурной среде, главной из которых является культурная идентификация личности. Посредством создания и циркуляции мобильной фотографии в Сети осуществляется процесс социальной и культурной интеграции, интеракции, формирование вкусов, предпочтений, стереотипов и норм, собирание групповой и личной идентичности, презентация самости, т. е. происходит своеобразный круговорот идентичности, где транслируется и переходит друг в друга субъективное и общекультурное.

Реализация и презентация культурной идентичности посредством мобильной фотографии происходит через идентификацию представителей молодого поколения с отчим домом, малой и большой родиной; знаковыми историческими событиями и людьми; объектами культурного и природного наследия. К креативным формам, акцентуирующим презентацию культурной идентичности, можно отнести постановочные фотографии, флешмобы, фотоакции и другие виды экспрессивной фотографии.

Если говорить об атрибутах, определяющих уникальность и своеобразие субъекта, то большой массив образуют фотографии, демонстрирующие сеть личных взаимоотношений и эмоциональную привязанность индивида к определенным объектам. Что же касается характерологических особенностей индивида, личной биографии и стиля жизни, они в фотографии выражены не так явно. Обращаясь к субъективной модальности, следует отметить доминирование в фотографиях позитивно окрашенной идентичности.

Таким образом, наша гипотеза о роли мобильной фотографии в современной молодежной культуре подтвердилась. Исследование визуального способно открыть более глубокие смыслы и значения, так как данный вид восприятия намного древнее знаково-символьного письма, что дает ему некоторые преимущества. Мобильная фотография как вид визуального творчества - это не только средство коммуникации, дань моде, вид развлечения. И хотя зачастую доминируют именно эти цели, она порождает новые знаки и смыслы, целые культурные пласты, социальные взаимосвязи, а значит, сопутствует развитию культуры как таковой.

\section{СПИСОК АИТЕРАТУРЫ}

Барт, Р. (2003) Фотографическое сообщение // Барт Р. Система Моды. Статьи по семиотике культуры / пер. с фр., вступ. ст. и сост. С. Н. Зенкина. М. : ИзА-во им. Сабашниковых. 512 с. C. $378-392$.

Барт, Р. (2011) Camera lucida. Комментарий к фотографии / пер. с фр., послесл. и коммент. М. Рыклина. М. : ООО «АА Маргинем Пресс». 272 с.

Гирц, К. (2004) Интерпретация культур : пер. с англ. М. : РОССПЭН. 560 с.

Ажемс, У. (1991) Психология : пер. с англ. / под ред. $\Lambda$. А. Петровской. М. : Педагогика. 368 с.

Зиммель, Г. (1996) Избранное : в 2 т. : пер. с нем. М. : Юрист. Т. 1: Философия культуры. 671 с. (Сер.: Аики культуры).

Кассирер, Э. (2002) Философия символических форм : [в 3 т.] М. ; СПб. : Университетская книга. Т. 1: Язык. 272 с.

Морен, Э. (2005) Метод. Природа Природы / пер. с фр., вступ. ст. Е. Н. Князевой. М. : Прогресс-Традиция. 464 с.

Хабермас, Ю. (1992) Модерн - незавершенный проект / пер. с нем. А. Б. Григорьева // Вопросы философии. № 4. С. 40-52.

Штомпка, П. (2007) Визуальная социология. Фотография как метод исследования : учебник / пер. с польск. Н. В. Морозовой, авт. вступ. ст. Н. Е. Покровский. М. : Аогос. 168 с. 
Bourdieu, P. (1985) Dialogue à propos de l'histoire culturelle // Actes de la recherche en sciences sociales. No. 59. P. 86-93.

Giménes, G. (1997) Materiales para una teoria de identidades sociales // Frontera norte. Vol. 9. No. 18. P. 9-28.

Solis, B. (2012) Meet Generation C: The connected customer [Электронный ресурс] // Brian Solis. April 9. URL: http://briansolis.com/2012/04/meet-generation-c-the-connected-customer/ [архивировано в WebCite] (дата обращения: 17.04.2015).

Аата поступления: 21.08.2015 2.

\section{THE PHENOMENON OF MOBILOGRAPHY AS A NEW FORM \\ OF IDENTITY REPRESENTATION \\ T. S. PANIOTOVA, M. V. MitrokHINA \\ (SOUTHERN FEDERAL UNIVERSITY, ROSTOV-ON-DON)}

In this article, we discuss the phenomenon of mobilography in the context of the contemporary cultural environment of youth and in close connection with the concept of cultural identity. We suggest that at this stage of social development, mobile photography can be understood as one of the means of youth's cultural self-identification, self-fashioning and representation.

Cultural identity, in our view, is one of the most important components of personal identity. We treat cultural identity as an intersubjective side of culture, or as a culture in itself, internalized in a specific way. Mobilography (mobile photography) is an umbrella term for amateur photos taken with devices that are not intended for professional photography. This worldwide phenomenon, now observable on the global scale, is explored here using semiotic and structural methodology, as well as that of cultural studies.

The article focuses on the outcomes of a theoretical and empirical study which we conducted in 2015 to detect newly emerging forms of representing cultural identity through certain genres of amateur photography. Also provided is a classification of such genres.

Our sources were photos Russians aged 16 to 30 years published on their personal pages in such social networks as VKontakte, Odnoklassniki, Instagram and Flickr. These social networks were chosen because of their popularity among young Russians and also thanks to the abundance of photo content. Overall, we studied and interpreted 1000 photos taken on a mobile phone by the owners of 100 profiles in social networks and/or blogs.

The fashioning and presenting of cultural identity via mobile photography occurs primarily through identifying with ancestral home, 'small' and 'large' Motherland, significant historical events and people, objects of cultural and natural heritage. Among the creative forms which accentuate exhibiting cultural identity, are staged photography, flash mobs, photo actions and other types of expressive photography.

Our study has shown that this phenomenon is an important way of cultural self-determination and self-presentation of youth, as it transforms identity-building, in particular its cultural aspects. Thus mobilography becomes a part of contemporary cultural creativity.

Keywords: identity; attributes of identity; cultural identity; mobilography; mobile photography; selfie; Internet communication; social networks; youth; representation; connotation; communication

\section{REFERENCES}

Barthes, R. (2003) Fotograficheskoe soobshchenie [The photographic message]. In: Barthes, R. Sistema Mody. Stat' $i$ po semiotike kul'tury [The fashion system. Articles on the semiotics of culture]/ transl. from French, introduction and comp. by S. N. Zenkin. Moscow, Tipografiia im. Sabashnikovykh Publ. 512 p. Pp. 378-392. (In Russ.).

Barthes, R. (2011) Camera lucida. Kommentarii $k$ fotografii [Camera lucida: Reflections on photography]/ transl. from French, afterword and comm. by M. Ryklin. Moscow, Ad Marginem Press. 272 p. (In Russ.). 
Geertz, C. (2004) Interpretatsiia kul'tur [The interpretation of cultures]. Moscow, ROSSPEN Publ. 560 p. (In Russ.).

James, W. (1991) Psikhologiia [Psychology] / transl. from English ; ed. by L. A. Petrovskaia. Moscow, Pedagogika Publ. 368 p. (In Russ.).

Simmel, G. (1996) Izbrannoe [Selected works] : in 2 vols. / transl. from German. Moscow, Iurist Publ. Vol. 1: Filosofiia kul'tury [Philosophy of culture]. 671 p. (Series: Liki kul'tury [Faces of culture]). (In Russ.).

Cassirer, E. (2002) Filosofiia simvolicheskikh form [The philosophy of symbolic forms] : [in 3 vols.] Moscow ; St. Petersburg, Universitetskaia kniga Publ. Vol. 1: Iazyk [Language]. 272 p. (In Russ.).

Morin, E. (2005) Metod. Priroda Prirody [Method. The Nature of Nature]/ transl. from French, introduction by E. N. Kniazeva. Moscow, Progress-Traditsiia Publ. 464 p. (In Russ.).

Habermas, J. (1992) Modern - nezavershennyi proekt [Modernity - An incomplete project] / transl. from German by A. B. Grigoriev. Voprosy filosofii, no. 4, pp. 40-52. (In Russ.).

Sztompka, P. (2007) Vizual' naia sotsiologiia. Fotografiia kak metod issledovaniia [Visual sociology. Photography as a method of research]/ transl. from Polish by N. V. Morozova, introduction by N. E. Pokrovskii. Moscow, Logos Publ. 168 p. (In Russ.).

Bourdieu, P. (1985) Dialogue à propos de l'histoire culturelle [A dialogue on cultural history]. Actes de la recherche en sciences sociales, no. 59, pp. 86-93. (In Fr.).

Giménes, G. (1997) Materiales para una teoria de identidades sociales [Materials for a theory of social identities]. Frontera norte, vol. 9, no. 18, pp. 9-28. (In Sp.).

Solis, B. (2012) Meet Generation C: The connected customer. Brian Solis, April 9. [online] Available at: http://briansolis.com/2012/04/meet-generation-c-the-connected-customer/ [archived in WebCite] (accessed 17.04.2015).

Submission date: 21.08 .2015$.

Паниотова Таисия Сергеевна - доктор философских наук, профессор кафедры теории культуры, этики и эстетики Института философии и социально-политических наук Южного федерального университета. Адрес: 344065, Россия, г. Ростов-на-Аону, Анепровский пер., А. 116. Тел.:+7 (863) 250-72-77. Эл. алpec: tspaniotova@mail.ru

Митрохина Мария Владимировна - бакалавр направления «культурология» Института философии и социально-политических наук Южного федерального университета. Адрес: 344011, Россия, г. Ростов-на-Аону, ул. Народного ополчения, д. 163. Тел.: +7 (863) 250-72-77. Эл. aдpec: kioto-7@mail.ru. Научный руководитель - д-р филос. наук, проф. Т. С. Паниотова.

Paniotova Taisia Sergeevna, Doctor of Philosophy, Professor, Department of Theory of Culture, Ethics and Aesthetics, Institute of Philosophy and Socio-political Sciences, Southern Federal University. Postal address: 116 Dneprovskiy Lane, 344065 Rostov-on-Don, Russian Federation. Tel.: +7 (863) 250-72-77. E-mail: tspaniotova@mail.ru

Mitrokhina Maria Vladimirovna, Bachelor of Culturology, Institute of Philosophy and Sociopolitical Sciences s, Southern Federal University. Postal address: 163 Narodnogo opolcheniya St., 344011 Rostov-on-Don, Russian Federation. Tel. +7 (863) 250-72-77. E-mail: kioto-7@mail.ru. Research advisor: T. S. Paniotova, Doctor of Philosophy, Professor. 